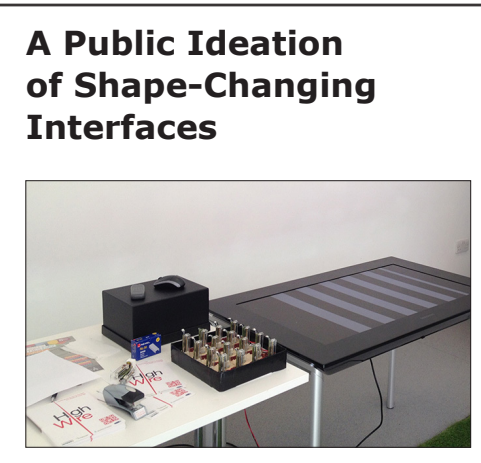

To expose and document a range of applications for shape-change, we employed unstructured brainstorming within a public engagement study [10]. A 74-participant brainstorming exercise with members of the public produced 336 individual ideas that were coded into 11 major themes: entertainment, augmented living, medical, tools \& utensils, research, architecture, infrastructure, industry, wearables, and education \& training. This paper documents the methodology and resultant application ideas along with reflections on the approach for gathering application ideas to enable shapechanging interactive surfaces and objects.

\title{
Drawing Design Futures for Shape-Changing Interfaces
}

Miriam Sturdee

Highwire DTC

Lancaster University

UK

m.sturdee@lancaster.ac.uk

\begin{abstract}
Shape-Changing interfaces have the potential to change the world by giving tangible form to computational interactions: but what will we use them for, and what are the implications of adopting such technologies? This doctorate investigates the current breadth of research prototypes, their classifications, limitations and possibilities - with the ultimate goal of informing application design and usage for shape-change. The interdisciplinary nature of this enquiry employs mixed methodologies such as sketching user scenarios and creating design fictions to inform the field, whilst public facing workshops allow for fresh perspectives on future design and use cases.
\end{abstract}

\section{Author Keywords}

Shape-Change; Sketching; User Experience; Design Fiction; Public Engagement;

\section{ACM Classification Keywords}

Permission to make digital or hard copies of part or all of this work for personal or classroom use is granted without fee provided that copies are not made or distributed for profit or commercial advantage and that copies bear this notice and the full citation on the first page. Copyrights for third-party components of this work must be honored. For all other uses, contact the Owner/Author.

DIS'17 Companion, June 10-14, 2017, Edinburgh, United Kingdom

(C) 2017 Copyright is held by the owner/author(s).

ACM ISBN 978-1-4503-4991-8/17/06.

http://dx.doi.org/10.1145/3064857.3079170

This is the author's version of the work. It is posted here for your personal use. Not for redistribution. The definitive Version of Record was published in DIS'17 Extended Abstrcts, http://dx.doi.org/10.1145/3064857.3079170
H. 5 . m. Information interfaces and presentation:

Miscellaneous.

Shape-changing interfaces represent the next step in physical computing: these devices are tangible - often self-actuating - technologies straddling a number of materials, mechanisms and applications. They have the potential to engage with our emotions $[6,8]$, add dimensionality to data $[7,12]$ and utilise multiple

\section{Introduction}




\section{Using Design Fiction to Inform Shape-Changing Interface Design and Use}

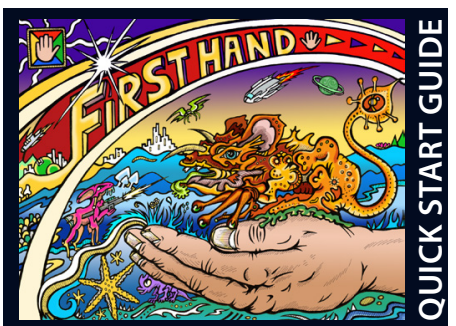

We propose the use of design fiction to investigate potential applications for this technology: using design fiction to create artifacts relating to future use scenarios for shape-change. Whilst research within shape change often proposes future usecases for prototypes during discussion, they are seldom in a form that presents them as everyday artifacts. Here, we present and discuss a printed gameplay instruction manual for a truly high resolution shape-changing game entitled First Hand, which aims to draw parallels between current gaming practices and the tangible nature of shapechanging interfaces [11]. sensory inputs and outputs [3, 5].

The current limiting factor in the development, and ultimately, the adoption of shape-change is the current prototypical nature of the field, and lack of forward planning with regards to potential use cases, applications and products. Research typically focuses on short term user studies with small numbers of academic-based participants as proof of concept, often abandoning the prototype at the end of a research project, or simply moving on to the next exciting device made possible by an ever-changing field. The question thus remains: What is shape-change good for? Further, do we need or want this technology?

In order to begin to answer this question, we conducted a large scale study in a public setting, asking participants to generate application ideas for shape-changing technology. ShapeClip [2] prototyping tools were used as boundary objects in order to explain the concept to a non-expert audience. The response was exceptional, 336 ideas were generated by 74 participants, spanning 11 categories (see sidebar on the first page). These ideas were often written, but many participants shared their thoughts as sketches: these sketches showed more than just basic concepts, they also showed glimpses into the world in which they might exist.

Designerly sketching around the theme of shape-change has primarily been addressed by Rasmussen et al. [9] but also in a limited form by other researchers as part of the on-going design process for prototyping and idea generation [4]. Within other fields, such as engineering, students are commonly encouraged to use hand-sketching to explore ideas, but it is often under-utilised in STEM subjects partially due to the idea that "I can't draw" [1], and partially due to the advent of computer-aided design programs. The visual nature of such data made it possible for the researcher to develop sketches into detailed user scenarios in the style of design fiction, that is, the products shown are not yet developed, but are shown as integrated into everyday life.

Based on the success of the public ideation study, the decision was made to expand the investigation to include a wider variety of examples of shape-change. A systematic review of shape-changing interfaces was undertaken (based on the criteria of more than one type of input and output occurring on the same surface) and all prototypes analysed for common features before being classified into seven hardware categories. These types of hardware were then designed in a low-fidelity format so that the interactive properties of all types of shape-change can be mimicked on a small scale, and thus demonstrated to varying audiences.

The low-fidelity shape-changing interfaces will be part of a large scale study using non-expert participants who will generate ideas and sketched data with which to co-create illustrated design fiction scenarios utilising shape-changing technology as it might exist in our future. The final stage of investigation aims to consolidate the previous research into prototype classification, design sketching, user experience and design fiction in order to inform the design and use of shape-changing hardware and applications, with the intention of feeding this data back into the research community and ultimately helping to shape the direction of the field.

Funded by the RCUK Digital Economy Programme through the EPSRC (Grant Reference EP/G037582/1) 


\section{References}

1. Cohn, Neil. 2012. Explaining 'I can't draw': Parallels between the structure and development of language and drawing. Human Development 55, 4, 167-192. http://doi.org/10.1159/000341842

2. John Hardy, Christian Weichel, Faisal Taher, John Vidler, and Jason Alexander. 2015. Shapeclip: towards rapid prototyping with shape-changing displays for designers. In Proceedings of the 33rd Annual ACM Conference on Human Factors in Computing Systems, ACM, 19-28. http://doi.org/10.1145/2702123.2702599

3. Isak Herman, Leonardo Impett, Patrick KA Wollner, and Alan F. Blackwell. 2015. Augmenting Bioacoustic Cognition with Tangible User Interfaces. In

International Conference on Augmented Cognition, Springer International Publishing, 437-448. http://doi. org/10.1007/978-3-319-20816-9 42

4. Hiroshi Ishii, Dávid Lakatos, Leonardo Bonanni, and Jean-Baptiste Labrune. 2012. Radical atoms: beyond tangible bits, toward transformable materials. interactions 19, 1, 38-51. http://doi.org/ 10.1145/2065327.2065337

5. Cindy Hsin-Liu Kao, Ermal Dreshaj, Judith Amores, Sang-won Leigh, Xavier Benavides, Pattie Maes, Ken Perlin, and Hiroshi Ishii. 2015. clayodor: Retrieving Scents through the Manipulation of Malleable Material." In Proceedings of the Ninth International Conference on Tangible, Embedded, and Embodied Interaction, ACM, 697-702. http://doi. org/10.1145/2677199.2688814

6. Matthijs Kwak, Kasper Hornbæk, Panos Markopoulos, and Miguel Bruns Alonso. 2014. The design space of shape-changing interfaces: a repertory grid study. In Proceedings of the 2014 conference on Designing interactive systems, ACM, 181-190. http://doi. org/10.1145/2598510.2598573

7. Daniel Leithinger, Sean Follmer, Alex Olwal, and
Hiroshi Ishii. 2015. Shape Displays: Spatial Interaction with Dynamic Physical Form." IEEE computer graphics and applications 35, no. 5, 5-11. http://doi. org/10.1109/MCG.2015.111

8. Majken Kirkegaard Rasmussen, Erik Grönvall, Sofie Kinch, and Marianne Graves Petersen. 2013. It's alive, it's magic, it's in love with you: opportunities, challenges and open questions for actuated interfaces. In Proceedings of the 25th Australian ComputerHuman Interaction Conference: Augmentation, Application, Innovation, Collaboration, ACM, 63-72. http://doi.org/10.1145/2541016.2541033

9. Majken Kirkegård Rasmussen, Giovanni Maria Troiano, Marianne Graves Petersen, Jakob G. Simonsen, and Kasper Hornbæk. 2016. Sketching Shape-changing Interfaces: Exploring Vocabulary, Metaphor Use, and Affordances. In Proceedings of the $2016 \mathrm{CHI}$ Conference on Human Factors in Computing Systems, ACM, 2740-2751. http://doi. org/10.1145/2858036.2858183

10. Miriam Sturdee, John Hardy, Nick Dunn, and Jason Alexander. 2015. A public ideation of shape-changing applications. In Proceedings of the 2015 International Conference on Interactive Tabletops \& Surfaces, ACM, 219-228. http://doi.org/ 10.1145/2817721.2817734

11. Miriam Sturdee, Paul Coulton and Jason Alexander. 2017. Using Design Fiction to Inform Shape-Changing Interface Design and Use. In Proceedings of the European Academy of Design 12: Design for Next.

12. Faisal Taher, John Hardy, Abhijit Karnik, Christian Weichel, Yvonne Jansen, Kasper Hornbæk, and Jason Alexander. 2015. Exploring interactions with physically dynamic bar charts. In Proceedings of the 33rd Annual ACM Conference on Human Factors in Computing Systems, ACM, 3237-3246. http://doi. org/10.1145/2702123.2702604 